\title{
O EXERCÍCIO DA LIBERDADE DE EXPRESSÃO NAS REDES SOCIAIS: E O MARCO CIVIL DA INTERNET
}

\author{
THE FREEDOM OF EXPRESSION EXERCISE IN SOCIAL NETWORKS: \\ THE INTERNET AND CIVIL MARCO
}

Flávia Piva Almeida Leite

\begin{abstract}
Doutora em Direito do Estado pela PUC/SP. Professora titular do Programa de Mestrado em Direito da Sociedade da Informação da Faculdades Metropolitanas Unidas - FMU/SP. E-mail: flaviaaleite3@ hotmail.com
\end{abstract}

Recebido em: 22/09/2015

Aprovado em: 28/03/2016

Doi: $10.5585 /$ rdb.v13i6.299

RESUMO: A utilização das redes sociais on-line, notadamente o Facebook e Twitter, vem crescendo com o passar dos anos, havendo a possibilidade de as pessoas escreverem o que têm vontade em seus perfis. Este estudo irá abordar a colisão entre os direitos de liberdade de expressão e da privacidade dos usuários da rede, com intuito de descobrir os limites jurídicos e as possíveis violações dessas garantias constitucionais frente à lei do Marco Civil da Internet. O método será o teórico dedutivo, com consultas bibliográficas, bem como pesquisas no mundo virtual de definições e exemplos.

PALAVRAS-CHAVE: Redes sociais; Liberdade de expressão; direito à privacidade; Marco civil da Internet.

ABSTRACT: The use of online social networks, particularly Facebook and Twitter, has grown over the years, with the possibility of people to write what they feel like in their profiles. This study will address the collision between the rights of freedom of expression and privacy of network users, aiming to find out the legal limits and possible violations of these constitutional guarantees front of the Civil Marco Internet law. The method is deductive theory, with bibliographic queries as well as research in the virtual world of definitions and examples.

KEYWORDS: Social networks; Freedom of expression; The right to privacy; Internet Civil Marco.

\section{INTRODUÇÃO}

Vivemos atualmente numa sociedade baseada essencialmente no desenvolvimento e disseminação das tecnologias de comunicação - daí a designação Sociedade da Informação - que nada mais é do que uma forma específica de 
organização social em que a gestão, o processamento e a transmissão de informações tornam-se as fontes fundamentais de produção e de poder, devido às novas condições tecnológicas surgidas nesse período histórico. O surgimento dessa nova sociedade trouxe, portanto, a necessidade de repensar o papel do Estado nesse novo contexto.

As redes sociais, sites, blogs, enfim, a internet revolucionou os comportamentos humanos, trazendo novas perspectivas para a vida em sociedade. Embora as vantagens que o uso da internet oferece, através dessas redes sociais, há também situações de riscos e novos conflitos que se apresentam aos seus usuários; dentre essas transformações podemos mencionar o conteúdo e limite que a liberdade de expressão e comunicação está sofrendo em um mundo cada vez mais interligado pela internet através das redes sociais.

Tais redes sociais on-line são meios de comunicação em que não só brasileiros, inclusive esses têm contato com qualquer pessoa. Transmitem e recebem informações instantaneamente, a todo tempo; há uma inserção nesse meio com bastante frequiência e intensidade. Entretanto, o que constatamos muitas vezes, é o desvio da finalidade dessas redes, porque os usuários passaram a escrever informações que com certa frequência violam a direitos e garantias fundamentais, praticados por pessoas muitas vezes escondidas por trás de apelidos, pseudônimos, cometendo crimes ocultados pelo anonimato, e ainda, muitas vezes, espalhando sua palavra de ódio.

Pois bem, os dois principais direitos dos usuários de internet que são violados quando se utiliza indevidamente as redes sociais são: os direitos de liberdade de expressão e à privacidade.

A liberdade de expressão não se refere somente à manifestação do pensamento, de ideias ou opiniões, pois também engloba as manifestações de sensações e sentimentos que podem ser externados pela atividade artística. A liberdade de expressão do pensamento pode ocorrer pelas mais variadas formas: escrita (livros, revistas, jornais, periódicos, cartas), falada (conversas, palestras, reuniões), pelo uso de imagens e de sons (rádio e televisão), internet através das redes sociais, entre os outros.

A liberdade de expressão do pensamento é um direito inerente ao ser humano que necessita se comunicar constantemente com o outro. A liberdade de expressão, por possibilitar essa manifestação não só do pensamento, mas de opiniões, ideias e ideologias, é a maneira pela qual o indivíduo participa da vida em sociedade e das decisões do Estado. Assim sendo, o Estado deve assegurar ao indivíduo o direito de expor e manifestar o seu pensamento livremente, sem sofrer qualquer restrição. Nesse particular veda o Texto Constitucional expressamente a censura e a licença.

Todavia, o exercício da liberdade de expressão do pensamento não é absoluto. Aliás, as restrições ao seu exercício constam do próprio Texto Constitucional; encontramos a vedação ao anonimato, a proibição de violação à honra, à imagem, à vida privada e à intimidade do indivíduo, e a obrigação de indenização por danos materiais ou morais no caso do seu exercício de forma abusiva. Portanto, apesar de permitir o pleno desenvolvimento da personalidade por meio de uma irradiação na comunicação e no nosso caso, através das redes sociais, encontra limites na razoabilidade da mensagem emitida, ou seja, é pressuposto que o emissor tenha o discernimento necessário para aferir o alcance positivo e até mesmo negativo do seu discurso.

Nesse contexto, foi aprovada a Lei n 12.965 , de 23 de abril de 2014 que já se tornou conhecida como Marco Civil da Internet, iniciado em 2009 por meio de consulta 
pública de duas fases, em 2011 ingressou no Congresso Nacional por meio da PL $\mathrm{n}^{\mathrm{o}}$ 2126/2011, de iniciativa do Poder Executivo.

\section{A INTERNET: AS REDES SOCIAIS}

Nos dias atuais, cada vez mais, as pessoas se organizam não em torno do que fazem, mas com base no que elas são ou acreditam quem são. Enquanto isso, as redes globais de intercâmbios instrumentais conectam e desconectam indivíduos, grupos, regiões e até países, de acordo com sua pertinência na realização dos objetivos processados na rede, em fluxo contínuo de decisões estratégicas. Segue-se uma divisão fundamental entre o instrumentalismo universal abstrato e as identidades particulares historicamente enraizadas. Nossas sociedades estão cada vez mais estruturadas em uma oposição bipolar entre a Rede e o Ser. ${ }^{1}$

Dentro desse contexto, a sociedade contemporânea vem adotando as Tecnologias de Informação e Comunicação (TCIs), em especial a internet, na vida social, econômica e pública, como um local aberto e propício ao fomento de debates relativos a temas que em outros tempos eram discutidos apenas de forma presencial.

Todavia, o surgimento da era digital, tem suscitado a necessidade de repensar importantes aspectos relativos à organização social, à democracia, à tecnologia, à privacidade, à liberdade etc. Segundo Newton de Lucca “... assim como a Revolução Industrial modificou, no passado as feições do mundo moderno, a ainda incipiente Revolução Digital já está transformando as faces do mundo pós-moderno". ${ }^{2}$

Dentre essas transformações podemos mencionar o conteúdo e limite que a liberdade de expressão e comunicação está sofrendo em um mundo cada vez mais interligado pela internet através das redes sociais.

A internet foi utilizada primeiramente pelos Estados Unidos, com finalidade bélica, passando, de mero meio de transmissão de informações a condição de local de encontro, debate e engajamento da defesa de movimentos sociais e políticos. Atualmente a internet é vista como um meio de comunicação que interliga dezenas de milhões de computadores no mundo inteiro e permite o acesso a uma quantidade de informações praticamente inesgotável, encurtando toda a distância de tempo e lugar.

Portanto, sob o aspecto técnico, a internet é uma imensa rede que liga elevado número de computadores em todo o planeta. E essas ligações surgem de inúmeras maneiras: redes telefônicas, cabos e satélites. Portanto, a rede telemática é uma oportunidade de encontros, de confronto, de troca de opiniões, de crescimento de relações interpessoais, com todas as vantagens e os riscos das relações sociais. ${ }^{3}$

Assim, com a internet surgem as redes sociais virtuais ou on line que são meios de comunicação em que não só brasileiros, mas outros cidadãos têm a possibilidade de ter contato com qualquer pessoa. Transmitem e recebem informações a todo tempo, de forma instantânea. Porém, nota-se que ocorre um desvio da finalidade das redes, porque

\footnotetext{
${ }^{1}$ Cf. CASTELLS, Manuel. A Sociedade em Rede (A era da informação: economia, sociedade e cultura; v.1. São Paulo: Paz e Terra, 9a edição, Trad. Roneide Venancio Majer, 2006, p. 41.

${ }^{2}$ Cf. LUCCA, Newton de. Prefácio da $3^{\mathrm{a}}$ edição da obra Direito digital de Patrícia Peck Pinheiro. $5^{\mathrm{a}}$ edição. Editora Saraiva: São Paulo, 2014, p. 31.

3 Cf. PAESANI, Lilliana Minardi. Direito e internet. Liberdade de informação, privacidade $e$ responsabilidade civil. $6^{\text {a }}$ edição. Editora Atlas, São Paulo, 2013, p. 12.
}

Revista de Direito Brasileira | São Paulo, SP | v. 13 | n. 6 | p. 150 - 166 | jan./abr. 2016 
os usuários passaram a escrever informações que entram na esfera privada e outras ainda, que ferem outros direitos fundamentais, provocando danos de diversas formas. ${ }^{4}$ E assim, ultrapassando o direito à liberdade de expressão e pensamento.

Segundo aponta Martha Gabriel em sua obra Marketing na era digital, as redes sociais digitais são uma das formas de comunicação que mais crescem e difundem-se globalmente, alterando comportamentos e relacionamentos. E mais adiante, esclarece que a rede social é definida como uma estrutura social formada por indivíduos ou empresas, que são conectadas por um ou mais tipos específicos de interdependência, como amizade, parentesco, afinidade, trocas financeiras, relacionamento de crenças, relacionamento de conhecimento, relações sexuais etc. Portanto, é uma reunião da sociedade, cujo objetivo é buscar conectar pessoas e proporcionar a comunicação. Já as redes sociais na internet são páginas da web que criam mecanismos para facilitar a interação entre os seus membros, em diversos locais. ${ }^{5}$

Mas, segundo a mesma autora, há diferenças entre os termos redes sociais e mídias sociais. Esclarece que:

Se por um lado, redes sociais relacionam-se a pessoas conectadas em função de um interesse comum, mídias sociais associam-se a conteúdos (textos, imagem, vídeo etc) gerados e compartilhados pelas pessoas nas redes sociais. Dessa forma, tanto redes sociais como mídias sociais, em sua essência, não têm nada a ver com tecnologia, mas com pessoas e conexões humanas. A tecnologia apenas facilita e favorece a interação das pessoas e a criação e compartilhamento de conteúdos por elas. Assim, as redes sociais, como o Facebook, por exemplo, são plataformas que possibilitam, facilitam e potencializam a conexão de pessoas com outras pessoas, ampliando o alcance das redes sociais pessoais, e ferramentas de armazenamento e compartilhamento que alavancam o volume de mídias sociais criadas pelas pessoas. Assim, um site de redes sociais on-line é apenas uma plataforma tecnológica que favorece a atuação das pessoas para interagir e compartilhar conteúdos em suas redes sociais. ${ }^{6}$

As redes sociais no mundo virtual adquiriram grande importância e são muito utilizadas, uma vez que não existe concentração em uma única forma de relacionamento, mas um leque de espécies, além da horizontalidade das relações, não havendo hierarquia entre os participantes. Assim, essas redes sociais, tais como facebook $^{7}$ são uma forma bastante utilizada pelas pessoas nos dias atuais onde interagem com as demais por diversos motivos, seja trabalho, relacionamento, estudo, diversão etc. ${ }^{8}$. Cabe esclarecer que, por exemplo, o Facebook em seu relatório de 2013 sobre pedidos de informação feito por países, indica que restringiu o conteúdo em resposta a casos relacionados á difamação e outros pedidos em casos de matéria civil, no entanto, não revelou o número de remoções que foram feitas. De acordo com os

\footnotetext{
${ }^{4}$ Cf. CARVALHO, Antonia Rafaela Fernandes. Twitter e facebook: liberdade de expressão e vida privada. Revista Direito e Liberdade. Natal, p. 41.

${ }^{5}$ Cf. GABRIEL, Martha. Marketing na era digital. São Paulo: Novatec, 2010, p. 193/194.

${ }^{6}$ Cf. GABRIEL, Martha. Marketing na era digital. São Paulo: Novatec, 2010, p. 202

${ }^{7}$ O Facebook foi criado pelo americano Mark Zuckerberg, quando este era aluno de Harvard, tendo inicialmente o nome Thefacebook. A rede funciona por meio de perfis e comunidades, podendo qualquer pessoa que deseje tornar-se membro criar uma conta. Ao realizar o cadastro e tornar-se membro, o primeiro passo é montar o perfil, em que são colocadas algumas informações pessoais. Feito o perfil, o indivíduo está pronto para formar a rede de amigos, bastando, para isso, ir ao perfil desejado, solicitar a amizade e aguardar a confirmação daquele membro. Essa rede social é uma forma bastante utilizada pelas pessoas atualmente para interagir com as demais por diversos motivos.

${ }^{8}$ Cf. CARVALHO, Antonia Rafaela Fernandes, p. 42.
} 
"padrões da comunidade no Facebook", os seguintes conteúdos poderão vir a ser removidos: se incitarem à violência ou apresentarem ameaça direta à segurança pública, bullying ou assédio, promoverem qualquer discurso de ódio e que pessoas sejam atacadas com base em sua raça, etnia, religião etc. Tais conteúdos não são removidos apenas com base no número de denúncias recebidas, mas através de um sistema automatizados que removem discursos públicos. E há casos também, em que conteúdos foram removidos pelo Facebook supostamente por violarem os termos de uso e geraram muita discussão, como foi o episódio envolvendo a remoção de fotos publicadas por participantes da "Marcha das Vadias", que mostraram mulheres com seios descobertos.

Contudo, o que percebemos é que mesmo com todos os avanços nas áreas de segurança hoje disponíveis, a internet ainda tem se prestado a permitir que algumas pessoas abusem de todo o seu potencial para comunicação e interação: nunca testemunhamos tantos crimes e violações a direitos e garantias fundamentais dentro (e fora) da grande rede em razão das relações dentro dela estabelecidas.

Como aponta Liliana Minardi Paesani, "a internet introduziu um outro elemento inovador: tornou a sociedade efetivamente transparente, possibilitando, a qualquer pessoa o acesso a uma quantidade máxima de informações em relação a qualquer outro aspecto da vida social". ${ }^{10}$

Assim, a cada dia que a passa a internet tem se tornado o meio de comunicação mais usado intensamente no mundo inteiro, com este uso freqüente por seus navegadores, surgem diversas redes sociais, onde cada um tem o livre aceso de publicação de sua vida, seus preceitos, seus gostos, suas políticas, bem como adicionar pessoas, postar fotos, jogos e uma infinidade de opções que proporciona na bendita e maldita rede social. Torna-se bendita porque é uma forma rápida e prática de contatar com o mundo afora, seja qual for o motivo; e maldita, porque muitos têm usado tais redes para denegrir a imagem humana, postando fotos íntimas nesses sites públicos, atacando com ofensas morais, o que tem ocasionado ofensa a direitos fundamentais, e gerado vários casos na justiça. ${ }^{11}$

Dentro desse contexto, pode-se verificar que os Estados têm se deparado, precipuamente, com alguns aspectos polêmicos no exercício da liberdade de expressão e do pensamento ocorridos nas redes sociais.

\section{LIBERDADE DE EXPRESSÃO DO PENSAMENTO}

A liberdade de expressão é um pilar tanto da democracia quanto do Estado de Direito, constitui um dos direitos fundamentais mais preciosos e corresponde a uma das mais antigas exigências humanas que encontra um dos seus principais fundamentos e

\footnotetext{
${ }^{9}$ Cf. BEATRIZ, Celina. Os direitos humanos e o exercício da cidadania no meio digital. In: LEITE, Geroge Salomão; LEMOS, Ronaldo (coord.). Marco Civil da internet. Editora: Altas, São Paulo, 2014, págs. .72, 73

${ }^{10}$ Cf. PAESANI, Liliana Minardi. O direito na sociedade da informação. (Coord.)São Paulo: Atlas, 2007,

${ }_{11}{ }^{4}$ Cf. TRENTIN, Taise Rabelo Dutra; TRENTIN, Sandro Seixas. Internet: publicações ofensivas em redes sociais e o direito à indenização por danos morais. Revista Direitos Emergentes na Sociedade Global. V.1, n.1, jan/jun/2012.ISSN 2316-3054, p. 81. Endereço de acesso: http://cascavel.cpd.ufsm.br/revistas/ojs-2.2.2/index.php/REDESG/article/viewFile/6263/pdf
}

Revista de Direito Brasileira | São Paulo, SP | v. 13 | n. 6 | p. 150 - 166 | jan./abr. 2016 
objetivo na dignidade da pessoa humana. "A liberdade de expressão é o direito fundamental que possibilita o exercício da soberania popular e pelo qual se concretizam as virtudes republicanas, uma vez que torna os cidadãos capazes de escolher, fiscalizar, contestar e exigir o devido exercício dos Poderes". ${ }^{12}$

Assim, a liberdade de expressão (gênero), apesar das peculiaridades do direito constitucional positivo brasileiro, que engloba a liberdade de manifestação de pensamento (incluindo a liberdade de opinião), a liberdade de expressão artística, a liberdade de ensino e pesquisa, a de comunicação e de informação (liberdade de imprensa) e a liberdade religiosa. Neste sentido, em princípio todas as formas de manifestação, desde que não violentas, estão amparadas pela liberdade de expressão, incluindo, "gestos, sinais, mensagens orais e escritas, bem como as manifestações veiculadas pelos modernos meios de comunicação, como nas redes sociais. ${ }^{13}$

Nesse sentido afirma J.J. Gomes Canotilho que:

A liberdade de expressão permite assegurar a continuidade do debate intelectual e do confronto de opiniões, num compromisso crítico permanente. Com essa qualidade, ela integra o sistema constitucional de direitos fundamentais, deduzindo-se do valor da dignidade da pessoa humana e dos princípios gerais de liberdade e igualdade, juntamente com a inerente exigência de proteção jurídica. A liberdade de expressão em sentido amplo é um direito multifuncional, que se desdobra num cluster de direitos comunicativos fundamentais (Kommunikationsgrudrechte) que dele decorrem naturalmente, como seja, por exemplo, a liberdade de expressão stricto sensu, de informação, de investigação acadêmica, de criação artística, de edição, de jornalismo, de imprensa, de radiodifusão, de programação, de comunicação individual, de telecomunicação e comunicação em rede. As liberdades comunicativas encontram-se ainda associadas a outras liberdades, como a liberdade de profissão, a livre

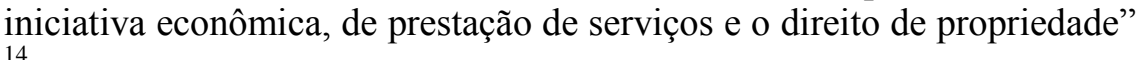

Desde a Declaração de Direitos do Homem e do Cidadão, fruto da Revolução Francesa de 1789, a garantia de exercício das liberdades, realce dado à livre comunicação do pensamento e de opinião, foi erigido em ponto nuclear do sistema. A Declaração Universal dos Diretos Humanos da ONU, de 1948, também dispôs, em seu art. 19: "Todo o indivíduo tem direito à liberdade de opinião e de expressão, o que implica o direito de não ser inquietado pelas suas opiniões e o de procurar, receber e difundir, sem consideração de fronteiras, informações e ideias por qualquer meio de expressão". No âmbito do direito internacional regional, essa mesma garantia de liberdade está prevista na Convenção Americana de Direitos Humanos de 1969, vigorando internacionalmente desde 18.7.1978, e ratificada pelo Brasil em 25.9.1992, internalizada pelo decreto da Presidência da República do Brasil de 6.11.1992. A

\footnotetext{
${ }^{12}$ Cf. GONÇALVES, Nicole P. S. Mader. Liberdade de expressão e Estado democrático de direito. In: Direito constitucional brasileiro. Teoria da constituição e direitos fundamentais. Clemerson Merlin Cléve (coord.). Editora Thomson Reuters: Revista dos Tribunais, São Paulo, 2014, p. 391.

${ }^{13}$ Cf. MITIDIERO, Daniel; SARLET, Ingo Wolfgang Sarlet; MARINONI, Luiz Guilherme. Curso de direito constitucional. $3^{\mathrm{a}}$ edição, Editora RT:Revista dos Tribunais, São Paulo, 2014, p. 458.

${ }^{14}$ Cf. CANOTILHO, J. J. Gomes; MACHADO, Jónatas E. M.. Constituição e código civil brasileiro: âmbito de proteção de biografias não autorizadas. In: JÚNIOR, Antônio Pereira Gaio; SANTOS, Márcio Gil Tostes dos. Constituição Brasileira de 1988. Reflexões em comemoração ao seu $25^{\circ}$ aniversário. Curitiba: Juruá, 2014, p. 132.
} 
Convenção Europeia de Direitos Humanos, adotada em 1953 pelo Conselho da Europa. A Carta Africana de Direitos Humanos e dos Povos, de 1986, prevê, em seu art. $9^{\circ}$. E na Carta dos Direitos Fundamentais da União Europeia, de 2000, se tem, no art. 11: "Liberdade de expressão e de informação 1. Todas as pessoas têm direito à liberdade de expressão. Este direito compreende a liberdade de opinião e a liberdade de receber e de transmitir informações ou ideias, sem que possa haver ingerência de quaisquer poderes públicos e sem consideração de fronteiras. 2. São respeitados a liberdade e o pluralismo dos meios de comunicação social".

Nos textos constitucionais anteriores que antecederam a Constituição Federal de 1988, os direitos à liberdade de pensamento e expressão do pensamento foram também reconhecidos como direito fundamental. A Carta Imperial de 1824 assegurou em seu artigo 179; a Constituição de 1891, primeira promulgada na República assegurou em seu artigo 72; a de 1934 estabeleceu em seu artigo 113; a Carta outorgada em 1937, apesar de despojada de legitimidade pelas suas origens e de efetividade pelos fins dos detentores do poder de então, não deixou de assegurá-la em seu artigo 122; a Constituição de 1946 em seu artigo 141; a Carta de 1967 estampou em seu artigo 150; a Emenda n. 1/1969 a trouxe em seu artigo 153.

Sobre a previsão expressa do direito à liberdade de expressão e de pensamento nos textos constitucionais acima mencionados, esclarece a Ministra do Supremo Tribunal Federal, Cármen Lúcia que:

... entre a letra da norma constitucional e a sua efetividade jurídico-social a distância pode ser grande se não se consolida o sentimento coletivo da Constituição, quer dizer o espírito que a anima não é apoderada pelo corpo sócio-político como elos da mesma experiência democrática.

O Brasil nunca teve carência de bons (às vezes ótimos) textos constitucionais e legais. $\mathrm{O}$ de que sempre se ressentiu foi de dar a eles cumprimento integral, para que a confiança de sua efetividade jurídica garantisse ao regime democrático a segurança jurídica dos cidadãos, finalidade estatal e social a se cumprir. ${ }^{15}$

A atual Constituição Federal brasileira prevê a liberdade de expressão como direito fundamental em especial em seus incisos IV, V, IX, X e XIV do artigo $5^{\circ}$, são meticulosos os princípios sobre liberdade de pensamento, de expressão de atividade artística, cultural, científica, dentre outras, sendo vedada a censura (art. $220, \S 2^{\circ}$ ).

Percebe-se que o Texto Constitucional pátrio conferiu ampla proteção à liberdade de pensamento ao reconhecê-la como direito fundamental e cláusula pétrea o que impede que qualquer meio estatal suprima essa garantia, ou venha, a pretexto de uma possível regulação, violar o seu núcleo essencial. Para que a regulamentação à liberdade de expressão seja legítima ela deve se fundamentar no Texto Constitucional.

Todavia, os direitos fundamentais não são absolutos, portanto a liberdade de expressão e de pensamento dada sua relevância para a democracia e o pluralismo político, não está absolutamente imune a qualquer limite e restrição. Há algumas limitações à liberdade de expressão previstas no próprio texto da Constituição, outras

\footnotetext{
${ }^{15}$ Ação Direta de Inconstitucionalidade 4.815/DF. Voto da Ministra Cármen Lúcia Relatora dessa Ação no STF, item 25 , páginas 43/44.
}

Revista de Direito Brasileira | São Paulo, SP | v. 13 | n. 6 | p. 150 - 166 | jan./abr. 2016 
previstas em lei, como a proibição de discursos racistas ${ }^{16}$ e difamatórios, ou ainda, os chamados crimes contra a honra (injuria, calúnia e difamação) ${ }^{17}$, a criminalização da pedofilia infantil por meios digitais 18 etc e, as decorrentes de ponderação jurisprudencial em confrontos entre princípios e regras de mesmo padrão normativo.

\section{LIMITES À LIBERDADE DE EXPRESSÃO DO PENSAMENTO: DIREITO À PRIVACIDADE}

A garantia da liberdade de expressão pressupõe um sistema estruturado e organizado da liberdade em harmonia com os demais valores protegidos pelo ordenamento jurídico. A proteção à liberdade de expressão não é absoluta.

A expressão de ideias é passível de restrições, na exata medida em que se devem respeitar outros valores albergados pela Constituição da República, com repercussão na legislação infraconstitucional. O próprio Texto Constitucional de 1988 traz restrições expressas à liberdade de expressão, quais sejam, a vedação do anonimato, a proteção à imagem, à honra, à intimidade e à privacidade, bem como o direito de resposta no caso de abuso do direito de liberdade de expressão do pensamento do indivíduo. ${ }^{19}$

A garantia à liberdade de expressão assegurada na Constituição leva em consideração também a licitude e o objeto da atividade de comunicação. A legislação infraconstitucional também regulamenta os limites ao exercício da liberdade de expressão. Todavia, essas restrições devem ser sempre fundamentadas, devem respeitar certos requisitos, como o de estarem expressamente previstas em lei, obedecerem ao princípio da proporcionalidade e a finalidade visada tem de ser legitima. ${ }^{20}$

O Estado liberal protege a liberdade de expressão do pensamento dos indivíduos, como um de seus fundamentos. Todavia, é imprescindível impor restrições ao seu exercício, pois do contrário ela pode representar a queda desse Estado. De um lado se garante a liberdade de expressão do pensamento como fortalecimento do Estado e, de outro, se asseguram normas que punem eventuais abusos no seu exercício.

Dentre os limites impostos pela Constituição ao exercício da liberdade de expressão do pensamento, mas de aplicação às liberdades de expressão em geral, destaca-se a vedação do anonimato. Tal proibição foi prevista no artigo $5^{\circ}$, inciso IV da $\mathrm{CF} / 88$. Ela tem por finalidade evitar que violações à honra e à imagem das pessoas ocorram de forma inconsequente, sem que se possa identificar o responsável por essas ofensas e, por conseguinte, responsabilizá-lo. É garantido ao indivíduo o direito de manifestar opiniões, ideias, pensamento e sentimentos; no entanto, ao exercer essa faculdade ele pode vir a causar danos a outrem. Isso é algo natural em uma sociedade. ${ }^{21}$ Todavia a vedação ao anonimato não exclui o sigilo da fonte (art. 5, XIV, da CF).

\footnotetext{
${ }^{16}$ Ver Lei 7.716/1989.

${ }^{17}$ Artigos 138, 139 e 140 do Código Penal brasileiro.

${ }^{18}$ Artigo 241-A da Lei 8.069/90.

${ }^{19}$ Cf. MEYER- PFLUG, Samantha Ribeiro. Liberdade de Expressão e Discurso do Ódio. São Paulo: RT, 2009, p.82.

${ }^{20}$ Cf. SANJUÁN, Teresa Freixes. Libertades informativas e integración Europea, Biblioteca Jurídica de Bolsillo, n. 21, Madrid: Colex, 1996, p. 23.

${ }^{21}$ Cf. MEYER- PFLUG, Samantha Ribeiro. Liberdade de Expressão e Discurso do Ódio. São Paulo: RT, 2009, p.82.
} 
Assim como a Constituição Federal reconhece e protege a liberdade de expressão e do pensamento, há que se reconhecer que com palavras pode-se beneficiar auxiliar ou prejudicar alguém, insultar, enganar, provocar rebeliões, isto é, causar danos a terceiros. Daí ser assegurado no inciso V, do artigo $5^{\circ}$, da Lei Maior, o direito de resposta proporcional ao agravo, além da indenização por dano material, moral ou à imagem.

Nesse sentido, afirma J. J. Gomes Canotilho e Vital Moreira, que o direito de resposta consiste:

no instrumento de defesa das pessoas contra qualquer opinião ou imputação de caráter pessoal ofensiva ou prejudicial, ou contra qualquer notícia ou referência pessoal inverídica ou inexata e é independente, quer do possível direito à indenização dos danos sofridos (...), quer da eventual responsabilidade envolvida. ${ }^{22}$

Portanto, trata-se de um direito autônomo que não se confunde com a garantia da indenização por dano material, moral ou à imagem a que faz jus o ofendido no caso de violação de seus direitos. É um veículo de defesa da imagem, da honra, da intimidade e da privacidade do indivíduo. ${ }^{23}$

O direito de resposta por si só não é capaz de afastar o responsável pelas consequências oriundas do Direito Penal: o processo por calúnia, difamação ou injúria (arts. 138, 139 e 140 do Código Penal Brasileiro).

Nesse contexto, a Constituição de 1988 protege no art. 5ª inc. X, a inviolabilidade da intimidade, da vida privada, da honra e da imagem das pessoas, assegurando o direito à indenização pelo dano material ou moral decorrente de sua violação.

$\mathrm{O}$ direito à imagem integra o direito ao nome e o direito à palavra (sem prejuízo de outras dimensões da personalidade), o direito à identidade pessoal, enfim, diz respeito aos atributos externos de uma pessoa, seja ela física ou jurídica, são os traços característicos que são transmitidos à sociedade. Proíbe-se o uso indevido, sem autorização, de fotografias, filmes e gravuras do agente.

A Constituição protege a honra de uma pessoa física ou jurídica consistindo num bem tipicamente imaterial, vinculação à noção de dignidade da pessoa humana, pois diz respeito ao bom nome e à reputação dos indivíduos. ${ }^{24}$

Embora o texto constitucional brasileiro proteja tanto a privacidade quanto intimidade, e também alguns autores tracem uma distinção entre ambos os direitos, tal distinção é muito difícil de sustentar, principalmente em virtude da fluidez entre as diversas esferas da vida privada (incluindo a intimidade). A privacidade protege os comportamentos e acontecimentos atinentes aos relacionamentos pessoais em geral, incluindo as relações comerciais e profissionais, ao passo que a intimidade envolve as relações familiares suas amizades. Porém, havendo violação a esses direitos há de se averiguar qual o interesse público existente na divulgação de uma informação relativa à vida privada dos envolvidos.

\footnotetext{
${ }^{22}$ Cf. CANOTILHO, J. J. Gomes; MOREIRA, Vital. Constituição da república portuguesa anotada. Arts. 1 a 107, $4^{\text {a }}$ edição. Coimbra: Coimbra Editora, 2007, p. 575/576.

${ }^{23}$ Cf. MEYER- PFLUG, Samantha Ribeiro. Liberdade de Expressão e Discurso do Ódio. São Paulo: RT, 2009, p.87.

${ }^{24}$ Cf. MITIDIERO, Daniel; SARLET, Ingo Wolfgang Sarlet; MARINONI, Luiz Guilherme. Curso de direito constitucional. $3^{\text {a }}$ edição, Editora RT:Revista dos Tribunais, São Paulo, 2014, p. $437 / 439$
}

Revista de Direito Brasileira | São Paulo, SP | v. 13 | n. 6 | p. 150 - 166 | jan./abr. 2016 
A vida privada é um conceito mais amplo que engloba tanto o direito à privacidade quanto intimidade, como articula-se com outros direitos fundamentais, como é o caso da inviolabilidade do domicílio, que é o espaço onde se desenvolve a vida privada. A liberdade de expressão do pensamento não pode violar a imagem, a honra, a intimidade e a privacidade das pessoas. Essas garantias são limites ao exercício da liberdade de expressão do pensamento. ${ }^{25}$

Ao se examinar os limites impostos pela Constituição à liberdade de expressão do pensamento, verifica-se que, atualmente, o responsável pela violação desses limites tem sido em grande parte o particular e não o Estado. No caso de conflito entre liberdade de expressão do pensamento e direito à privacidade, tem-se que é o próprio particular o violador desse direito e não o ente estatal.

Nesse contexto, tem-se que a Constituição de 1988 protege a liberdade de expressão do pensamento tanto de violações por parte do Estado, como do particular, pois a sua violação pode partir do Estado, mas também de entes privados que detêm os meios de comunicação e do próprio particular.

Todavia, com o passar dos tempos verificou-se que em muitas situações o responsável pela violação dos direitos fundamentais não era o Estado, mas o próprio particular ou grupos sociais. Tal situação se vê agravada em um mundo onde as pessoas estão cada vez mais interligadas pela internet, na qual o fluxo de informação nunca foi tão grande, rápido e, por via de consequência as violações do direito à privacidade se tornam comuns. "Navegação de GPS, cartões inteligentes, pedágios eletrônicos em transportes, as câmeras públicas, inquéritos eletrônicos, scanners fixos ou móveis em qualquer lugar, todos de algum modo afetam nossa liberdade e privacidade." ${ }^{26}$ Assim, cabe ao Estado, por meio da edição de leis e políticas públicas, preservar o direito à privacidade e evitar eventuais abusos ao exercício do direito à liberdade de expressão do pensamento.

Assim, o ambiente virtual tornou-se propício para condutas odiosas que reclamam uma atitude enérgica do Poder Público. Dentro desse contexto, foi aprovada a Lei 12.965, de 23 de abril de 2014, conhecida como Marco Civil da Internet, que estabelece princípios, garantias, direitos e deveres para o uso da internet no Brasil.

Referida Lei está alicerçada por três pilares: neutralidade de rede, liberdade de expressão e privacidade. O respeito ao princípio da neutralidade da rede na internet veda a discriminação no tráfego de dados na internet em razão de seu conteúdo, origem e destino, serviço, terminal ou aplicação. No tocante ao segundo pilar, a Lei do Marco Civil reforça a garantia constitucional da liberdade de expressão no ambiente on line, procurando equilibrá-la com a proteção à intimidade, a honra e a imagem das pessoas. E, por fim, o terceiro pilar do Marco Civil introduz o tema da proteção de dados pessoais no sistema jurídico brasileiro.

Alguns aspectos sobre o direito à privacidade na internet merecem especial destaque e serão analisados sem a pretensão de exaurir o tema.

\footnotetext{
${ }^{25}$ Cf. FARIAS, Edilsom. Liberdade de expressão e comunicação: teoria e proteção constitucional, cit., p. 81.

${ }^{26}$ Cf. MOLINARO, Carlos Alberto; SARLET, Ingo Wolfgang. Breves notas acerca das relações entre a sociedade em rede, a internet e o assim chamado estado de vigilância. In: LEITE, George Salomão; LEMOS, Ronaldo (coord). Marco civil da internet; São Paulo: Atlas, 2014, p. 39
}

Revista de Direito Brasileira | São Paulo, SP | v. 13 | n. 6 | p. 150 - 166 | jan./abr. 2016 


\section{O DIREITO À PRIVACIDADE E O MARCO CIVIL DA INTERNET}

Como mencionamos anteriormente, nossa Constituição Federal assegurou a proteção à liberdade de expressão do pensamento (art. $\left.5^{\circ}, \mathrm{IV}\right)$, tendo sido incluída no rol de direitos fundamentais previstos no artigo $5^{\circ}$ e, justamente por existir outros direitos, não é absoluta. Vimos também que há algumas limitações a essa liberdade prevista em leis e na própria Lei Maior.

A era da sociedade de informação, que muda e dita comportamentos, regendo as formas de comunicação, os relacionamentos interpessoais, o consumo e a própria vida em sociedade, faz com que os direitos à liberdade de expressão e à privacidade dos usuários da internet se tornem algo capaz de extrapolar a própria pessoa. É o que Zygmunt Bauman denomina de danos colaterais da modernidade líquida, ao descrever os riscos da fusão entre espaços públicos e privados de maneira a arquitetar uma sociedade confessional, com graves restrições à liberdade. ${ }^{27}$

Portanto, a cada dia que passa a internet cria novos e tormentosos malefícios para a privacidade. $O$ problema se agrava à medida em que mais informações são compartilhadas em redes sociais, tais como Google, Facebook, Twitter, Linkedin etc. Os usuários se sentem à vontade para revelarem detalhes íntimos de suas vidas pessoais, fornecendo informações precisas, compartilhando fotografias e vivenciando $o$ fetichismo e exibicionismo de uma sociedade confessional. ${ }^{28}$

Para enfrentar estes problemas necessitamos repensar a privacidade para a era da informação. Assim, "a privacidade, hoje, abandonou a concepção clássica, pela qual seria vista como o direito de ser deixado em paz, ou o direito de estar só, passando o seu centro de gravidade à possibilidade de cada um controlar o uso das informações que lhe dizem respeito." 29

Dentro desse contexto, surge a Lei do Marco Civil, que se apresenta como uma grande moldura de direitos e liberdades individuais dos usuários da internet no contexto brasileiro. O referido texto começou a ser elaborado em 2009, pelo Ministério da Justiça em colaboração com o Centro de Tecnologia com sugestões da sociedade civil e especialistas, tendo como origem o Projeto de Lei ${ }^{\circ} 2.126 / 2011$, convertido em lei em 23 de abril de 2014. O texto entrou em vigor em 23 de junho de 2014, respeitando o prazo de 60 dias de vacatio legis, conforme previsto no artigo 32 da Lei do Marco Civil.

Cabe ressaltar que o Marco Civil da Internet é considerado uma Carta de Princípios, pois, já em seu Capítulo I, encontra-se o que a lei denomina fundamentos, princípios e objetivos do Marco Civil. Assim, em seu artigo $2^{\circ}$ definiu os fundamentos da disciplina do uso da internet: o reconhecimento da escala mundial da rede; os direitos humanos e o exercício da cidadania em meios digitais; a pluralidade e a diversidade; a abertura e a colaboração; a livre iniciativa, a livre-concorrência e a defesa do consumidor.

\footnotetext{
${ }^{27}$ Cf. BAUMANN, Zygmunt. Danos colaterais: desigualdades sociais numa era global. Tradução Carlos Alberto Medeiros. Rio de Janeiro: Zahar, 2013, p. 108.

${ }^{28}$ Cf. BAUMANM Zygmunt. Vida para o consumo: a transformação das pessoas em mercadorias. Tradução de Carlos Alberto Medeiros. Rio de Janeiro: Zahar, 2008, p. 8.

${ }^{29}$ Cf. . BAUMANN, Zygmunt. Danos colaterais: desigualdades sociais numa era global. Tradução Carlos Alberto Medeiros. Rio de Janeiro: Zahar, 2013, p. 108.

${ }^{29}$ Cf. BAUMANM Zygmunt. Vida para o consumo: a transformação das pessoas em mercadorias. Tradução de Carlos Alberto Medeiros. Rio de Janeiro: Zahar, 2008,
} 
Por sua vez, a Lei elencou em seu artigo $3^{\circ}$ os princípios norteadores do Marco Civil. E entre os objetivos que deverão ser permanentemente buscados trouxe no seu artigo $4^{\circ}$ a promoção do direito de acesso à internet a todos; de acesso à informação, ao conhecimento e à participação na vida cultural e na condução dos assuntos públicos; da inovação e do fomento à ampla difusão de novas tecnologias e modelos de uso e acesso; da adesão a padrões tecnológicos abertos que permitam a comunicação, a acessibilidade e a interoperabilidade entre aplicações e bases de dados.

Percebe-se que muitos desses conteúdos vão ao encontro de preceitos já plasmados na Constituição Federal. Porém, é importante ter em mente que o Marco Civil da Internet veio para regulamentar o uso da internet no contexto brasileiro já que a Lei Geral de Telecomunicações e a Lei 9.472/97 têm-se demonstrado insuficiente, uma vez que regulava uma realidade em que a internet não estava tão presente no nosso dia a dia, na verdade a internet inexistia no Brasil ao tempo da lei geral de telecomunicações.

Assim, a nova Lei trouxe um importante rol de princípios capazes de proteger usuários, empreendedores e a própria característica de abertura da internet. Nesse sentido discorre Lenio Luiz Streck que a internet é um museu de grandes novidades, em que o pamprincipiologismo ${ }^{30}$ é a menina dos olhos, pois afinal, princípios são normas. Mais adiante, assevera o mesmo autor, que "a nova lei insere-se num contexto contemporâneo em que os princípios jurídicos, as cláusulas abertas e os conceitos indeterminados são utilizados com o objetivo de possibilitar maior liberdade de conformação do direito pelo intérprete no caso concreto." 31

Já que vivemos cada vez mais interligados pela internet, a privacidade é um dos direitos individuais mais complexos da sociedade digital, tanto que a necessidade de sua proteção aparece na Lei como um dos princípios mais esmiuçados ao longo do texto legal.

$\mathrm{Na}$ Lei do Marco Civil a privacidade é tratada em diversos artigos (art. $3^{\circ}$, incisos II, III; art. $7^{\circ}$, incisos I, II, III, VII, VIII, letra $c$, IX, X; art. $8^{\circ}$, parágrafo único, inciso I; art. $10, \S \S 1^{\circ}, 2^{\circ}, 3^{\circ}$ e $4^{\mathrm{o}}$; art. 16, inciso II; artigo 23), "portanto, ganha em número de citações dos outros dois princípios também centrais da nova lei, que são neutralidade e liberdade de expressão". 32

Vejamos:

\author{
Art. $3^{0}$ A disciplina do uso da internet no Brasil tem os \\ seguintes princípios: \\ (...) \\ II- proteção da privacidade; \\ III- proteção dos dados pessoais, na forma da lei;
}

Art. $\mathbf{7}^{\mathbf{0}} \mathbf{O} \mathrm{O}$ acesso à internet é essencial ao exercício da cidadania, e ao usuário são assegurados os seguintes direitos:

\footnotetext{
${ }^{30}$ Cf. STRECK, Lenio Luiz. Verdade e consenso. 5 ed. São Paulo: Saraiva, 2014. A expressão pamprincipiologismo refere-se a um fenômeno marcado pela proliferação de princípios que consolidam uma leitura equivocada do conjunto princípiológico abarcado pelo Constitucionalismo Contemporâneo, em que os órgãos julgadores elaboram princípios ad hoc sem qualquer normatividade de forma discricionária.

31 Cf. STRECK, Lenio Luiz. Apontamentos hermenêuticos e o marco civil da internet. In: LEITE, Salomão George; LEMOS, Ronaldo. Marco civil da internet. São Paulo: Atlas, 2014, p. 333.

${ }^{32}$ Cf. PINHEIRO, Patrícia Peck. Abertura e colaboração como fundamentos do marco civil. In: LEITE, George Salomão; LEMOS, Ronaldo. (coord). Marco Civil da Internet. São Paulo: Atlas, 2014, p. 99.
}

Revista de Direito Brasileira | São Paulo, SP | v. 13 | n. 6 | p. 150 - 166 | jan./abr. 2016 
I - inviolabilidade da intimidade e da vida privada, sua proteção e indenização pelo dano material ou moral decorrente de sua violação;

II - inviolabilidade e sigilo do fluxo de suas comunicações pela internet, salvo por ordem judicial, na forma da lei;

III - inviolabilidade e sigilo de suas comunicações privadas armazenadas, salvo por ordem judicial;

(...)

VII - não fornecimento a terceiros de seus dados pessoais, inclusive registros de conexão, e de acesso a aplicações de internet, salvo mediante consentimento livre, expresso e informado ou nas hipóteses previstas em lei;

VIII - informações claras e completas sobre coleta, uso, armazenamento, tratamento e proteção de seus dados pessoais, que somente poderão ser utilizados para finalidades que:

(...)

c) estejam especificadas nos contratos de prestação de serviços ou em termos de uso de aplicações de internet;

IX - consentimento expresso sobre coleta, uso, armazenamento e tratamento de dados pessoais, que deverá ocorrer de forma destacada das demais cláusulas contratuais;

$\mathrm{X}$ - exclusão definitiva dos dados pessoais que tiver fornecido a determinada aplicação de internet, a seu requerimento, ao término da relação entre as partes, ressalvadas as hipóteses de guarda obrigatória de registros previstas nesta Lei;

(...)

Art. 8- A garantia do direito à privacidade e à liberdade de expressão nas comunicações é condição para o pleno exercício do direito de acesso à internet.

Parágrafo único. São nulas de pleno direito as cláusulas contratuais que violem o disposto no caput, tais como aquelas que:

I - impliquem ofensa à inviolabilidade e ao sigilo das comunicações privadas, pela internet; ou

(...)

Art. 10- A guarda e a disponibilização dos registros de conexão e de acesso a aplicações de internet de que trata esta Lei, bem como de dados pessoais e do conteúdo de comunicações privadas, devem atender à preservação da intimidade, da vida privada, da honra e da imagem das partes direta ou indiretamente envolvidas.

$\S 1^{\circ} \mathrm{O}$ provedor responsável pela guarda somente será obrigado a disponibilizar os registros mencionados no caput, de forma autônoma ou associados a dados pessoais ou a outras informações que possam contribuir para a identificação do usuário ou do terminal, mediante ordem judicial, na forma do disposto na Seção IV deste Capítulo, respeitado o disposto no art. $7^{\circ}$. 
$\S 2^{\underline{0}} \mathrm{O}$ conteúdo das comunicações privadas somente poderá ser disponibilizado mediante ordem judicial, nas hipóteses e na forma que a lei estabelecer, respeitado o disposto nos incisos II e III do art. $7^{\circ}$.

$\S 3^{0} \mathrm{O}$ disposto no caput não impede o acesso aos dados cadastrais que informem qualificação pessoal, filiação e endereço, na forma da lei, pelas autoridades administrativas que detenham competência legal para a sua requisição.

$\S 4^{\mathrm{o}}$ As medidas e os procedimentos de segurança e de sigilo devem ser informados pelo responsável pela provisão de serviços de forma clara e atender a padrões definidos em regulamento, respeitado seu direito de confidencialidade quanto a segredos empresariais.

Art. 16- Na provisão de aplicações de internet, onerosa ou gratuita, é vedada a guarda:

(...)

II - de dados pessoais que sejam excessivos em relação à finalidade para a qual foi dado consentimento pelo seu titular.

Art. 23- Cabe ao juiz tomar as providências necessárias à garantia do sigilo das informações recebidas e à preservação da intimidade, da vida privada, da honra e da imagem do usuário, podendo determinar segredo de justiça, inclusive quanto aos pedidos de guarda de registro."

Conforme se verifica da leitura dos dispositivos mencionados, a privacidade foi amplamente regulamentada na Lei do Marco Civil. Todavia, a rede foi construída, justamente para ser descentralizada. Logo, diversas violações a direitos fundamentais, notadamente à privacidade, derivadas do fluxo de dados advêm de outras localidades fora do território nacional e, portanto, excluídas da incidência do Marco Civil.

As redes sociais desempenham cada vez mais um papel central na vida dos cidadãos. A comunicação em rede tem sido explorada como instrumento de ativação de movimentos sociais e culturais como a luta de direitos humanos, ambientalistas, etc. Por meio delas, diversos protestos foram organizados e pessoas foram às ruas. Aqui, faz-se necessário relembrar o atentado ao jornal satírico "Charlie Hebdo", em Paris, na França, em 07 de janeiro de 2015, ocasionando a morte de 12 pessoas, sendo nove jornalistas, incluindo o editor-chefe, renomados cartunistas e dois policiais, além de ferirem outras 11. Esse episódio mobilizou a multidão, que se reuniu na Place de La Répulique. Ao mesmo tempo em que essa mobilização foi possibilitada presencialmente, ela também gerou uma intensa mobilização nas redes sociais com o slogan: Somos todos Charlie. Outro exemplo que podemos mencionar foi a denominada Primavera Árabe. Esse movimento foi uma onda de protestos e revoluções no Oriente Médio e no Norte da África que teve início em dezembro de 2010, na Tunísia. A marca do movimento foi a intensa mobilização de manifestantes pelas redes sociais, notadamente o Twitter. Cabe ressaltar que mesmo vivendo em países onde a liberdade de expressão praticamente inexiste, milhares de cidadãos conseguiram se conectar para ir às ruas contra governos autoritários.

A legislação doméstica por si só não dá conta das inúmeras violações de direitos presentes na rede mundial de computadores. Dentro desse contexto, esse tema merecerá um tratamento mais específico no plano internacional, de modo a incluir a agenda de

Revista de Direito Brasileira | São Paulo, SP | v. 13 | n. 6 | p. 150 - 166 | jan./abr. 2016 
direitos humanos. Embora "a legislação do Estado-Nação seja importante, como é o caso do Marco Civil brasileiro, ela é apenas a ponta do iceberg, uma vez que incapaz de proteger os direitos fundamentais violados pelos fluxos de dados mundiais". ${ }^{33}$

\section{CONCLUSÕES}

Atualmente vivemos numa época em que as pessoas passam a maior parte do dia conectadas à rede mundial de computadores e seus direitos são constantemente violados pela internet .

Como visto, as redes sociais passaram a ser um lugar de troca de informações, grupos de discussão e também de participação democrática. Todavia, esse ambiente social, muitas vez é mal utilizado, tornando-se propício para violar a liberdade de expressão do pensamento e o direito à privacidade.

Isso ocorre em grande parte em virtude da velocidade com que a informação se dissemina, bem como devido à dificuldade de se regular o conteúdo das informações que são veiculadas na internet, que tem como característica primordial ser um espaço livre.

Tanto o direito de liberdade de expressão do pensamento bem como o direito à privacidade são direitos fundamentais que estão assegurados expressamente em diversos dispositivos do nosso Texto Constitucional.

No entanto, a liberdade na internet, necessária à livre circulação de informações e ideias, bem como à consolidação da própria democracia, não pode ser sinônimo de violação de direitos individuais constitucionalmente assegurados e igualmente indispensáveis para a manutenção de um Estado Democrático de Direito.

Não há negar-se que novas tecnologias afetam e sempre afetarão o exercício do direito à liberdade de expressão do pensamento e a proteção à privacidade do indivíduo. O surgimento dessa nova sociedade trouxe, portanto, a necessidade de repensar o papel do Estado. Nessa toada surge, no âmbito nacional, a Lei do Marco Civil da Internet.

A Lei do Marco Civil da Internet veio ao encontro dessa nova sociedade, marcada por uma intensa revolução digital, também chamada de tecnológica, na qual o Brasil encontra-se inserido, principalmente, a partir do momento em que experimentado o ingresso da internet em nossas vidas.

Fazia-se imprescindível a necessidade de regular a internet para preservar os direitos individuais garantidos na Constituição. A Lei do Marco Civil da Internet fundamentou-se em três pilares: neutralidade da rede; privacidade de usuários e, liberdade de expressão do pensamento.

A privacidade foi amplamente assegurada no texto legal; todavia, o grande desafio que se apresenta é justamente o de fiscalizar a aplicação dos conteúdos normativos da Lei do Marco Civil da Internet. Essa tarefa deve ser desempenhada, tanto pelo Estado, quanto pela própria sociedade, na preservação do binômio: liberdade de expressão do pensamento versus proteção da privacidade. Cabe ressaltar que mesmo

${ }^{33}$ Cf. BOLZAN DE MORAIS, José Luis; JACOB NETO, Elias. Direitos fundamentais e surveillance: as antidemocarátias e assimétricas relações de visibilidade possibilitadas pela tecnologia da informação. In: CONPED; UNICURITBA (0rg). Direito e novas tecnologias. Florianópolis: FUNJAB, 2013, p. 234262.

Revista de Direito Brasileira | São Paulo, SP | v. 13 | n. 6 | p. 150 - 166 | jan./abr. 2016 
com o surgimento dessa legislação doméstica, ela, por si só, não dá e não dará conta das inúmeras violações de direitos presentes na rede mundial de computadores. Esse tema merecerá um tratamento mais específico e aprofundado no plano internacional, de modo a incluir a agenda de direitos humanos.

\section{REFERÊNCIAS}

BAUMANM Zygmunt. Vida para o consumo: a transformação das pessoas em mercadorias. Tradução de Carlos Alberto Medeiros. Rio de Janeiro: Zahar, 2008.

Danos colaterais: desigualdades sociais numa era global. Tradução Carlos Alberto Medeiros. Rio de Janeiro: Zahar, 2013.

BEATRIZ, Celina. Os direitos humanos e o exercício da cidadania no meio digital. In: LEITE, Geroge Salomão; LEMOS, Ronaldo (coord.). Marco Civil da internet. Editora: Altas, São Paulo, 2014.

BOLZAN DE MORAIS, José Luis; JACOB NETO, Elias. Direitos fundamentais $e$ surveillance: as antidemocarátias e assimétricas relações de visibilidade possibilitadas pela tecnologia da informação. In: CONPED; UNICURITBA (0rg). Direito e novas tecnologias. Florianópolis: FUNJAB, 2013.

CANOTILHO, J. J. Gomes; MOREIRA, Vital. Constituição da república portuguesa anotada. Arts. 1 a 107, 4ª edição. Coimbra: Coimbra Editora, 2007.

CANOTILHO, J. J. Gomes; MACHADO, Jónatas E. M.. Constituição e código civil brasileiro: âmbito de proteção de biografias não autorizadas. In: JÚNIOR, Antônio Pereira Gaio; SANTOS, Márcio Gil Tostes dos. Constituição Brasileira de 1988. Reflexões em comemoração ao seu $25^{\circ}$ aniversário. Curitiba: Juruá, 2014.

CARVALHO, Antonia Rafaela Fernandes. Twitter e facebook: liberdade de expressão e vida privada. - RDL - ESMARN - v. 15, n. 1, p. 39-69, jan./abr. 2013. Endereço eletrônico: file:///C:/Users/Usuario/Downloads/503-1746-3-PB\%20(5).pdf Acesso em 24 de agosto de 2015.

CASTELLS, Manuel. A Sociedade em Rede (A era da informação: economia, sociedade e cultura; v.1. São Paulo: Paz e Terra, 9a edição, Trad. Roneide Venancio Majer, 2006.

FARIAS, Edilsom. Liberdade de expressão e Comunicação: teoria e proteção constitucional. São Paulo: Revista dos Tribunais, 2004.

GABRIEL, Martha. Marketing na era digital. São Paulo: Novatec, 2010.

GONÇALVES, Nicole P. S. Mader. Liberdade de expressão e Estado democrático de direito. In: Direito constitucional brasileiro. Teoria da constituição e direitos fundamentais. Clemerson Merlin Cléve (coord.). Editora Thomson Reuters: Revista dos Tribunais, São Paulo, 2014. 
LUCCA, Newton de. Prefácio da $3^{\mathrm{a}}$ edição da obra Direito digital de Patrícia Peck Pinheiro. $5^{\text {a }}$ edição. Editora Saraiva: São Paulo, 2014.

MEYER- PFLUG, Samantha Ribeiro. Liberdade de Expressão e Discurso do Ódio. São Paulo: RT, 2009,p.82.

MITIDIERO, Daniel; SARLET, Ingo Wolfgang Sarlet; MARINONI, Luiz Guilherme. Curso de direito constitucional. $3^{\mathrm{a}}$ edição, Editora RT:Revista dos Tribunais, São Paulo, 2014, p. 458.

MOLINARO, Carlos Alberto; SARLET, Ingo Wolfgang. Breves notas acerca das relações entre a sociedade em rede, a internet e o assim chamado estado de vigilância. In: LEITE, George Salomão; LEMOS, Ronaldo (coord). Marco civil da internet; São Paulo: Atlas, 2014.

PAESANI, Liliana Minardi. O direito na sociedade da informação. (Coord.) São Paulo: Atlas, 2007.

Direito e internet. Liberdade de informação, privacidade e responsabilidade civil. 6 $6^{\text {a }}$ edição. Editora Atlas, São Paulo, 2013.

PINHEIRO, Patrícia Peck. Abertura e colaboração como fundamentos do marco civil. In: LEITE, George Salomão; LEMOS, Ronaldo. (coord). Marco Civil da Internet. São Paulo: Atlas, 2014.

SANJUÁN, Teresa Freixes. Libertades informativas e integración Europea, Biblioteca Jurídica de Bolsillo, n. 21, Madrid: Colex, 1996.

TRENTIN, Taise Rabelo Dutra; TRENTIN, Sandro Seixas. Internet: publicações ofensivas em redes sociais e o direito à indenização por danos morais. Revista Direitos Emergentes na Sociedade Global. V.1, n.1, jan/jun/2012.ISSN 2316-3054,. Endereço de acesso:

http://cascavel.cpd.ufsm.br/revistas/ojs2.2.2/index.php/REDESG/article/viewFile/6263/pdf Acesso em 24 de agosto de 2015. 